\title{
In the eye of the storm: English local government and the COVID-19 crisis
}

\begin{abstract}
The COVID-19 crisis has exposed the problematic nature of centre-local relations in the UK. This is particularly true in England, where the centre maintains a strong hold over the subnational governance. The aim of this chapter is to shed light on this issue, assessing how the presence of systemic weaknesses in multi-level governance structures has affected pandemic responses since the start of the coronavirus emergency in England. On the one hand, the analysis shows the resilience of the local level, emphasising the potential of place-based responses and locally rooted leadership against the top-down approach endorsed by the centre. On the other hand, however, it also indicates the persistence of central government's dominance over local authorities. This has led to a growing chasm between central and local government, which impacts negatively on policy outcomes and requires to be addressed through a reform of vertical relationships and power allocation in England.
\end{abstract}

Keywords: Covid-19; local government; devolution; multi-level governance; policy blunders; England.

In many respects, the outbreak of COVID-19 has thrown into sharp relief the issues that underpin the UK's system of territorial governance. This is particularly evident in England, where subnational governance remains highly centralised. From the start of the pandemic, local government has been in the eye of a 'perfect storm'. On the one hand, local authorities had to tackle an increasing number of challenges to keep providing essential services to the communities they serve, showing resilience and resolve despite the toll taken by a decade of austerity on them. On the other, they have been side-lined by central government in crucial policy decisions, finding themselves at the receiving end of top-down measures that hampered the effective management of the crisis on the ground. The absence of a coherent system of devolution and constitutional protection for local government have further aggravated this situation.

In this way, COVID-19 has exposed the limits of the Westminster model, laying bare the dysfunctional nature of centre-local relations in England. The aim of this contribution is to shed light on this issue. To achieve this, the chapter is organised as follows. Firstly, it will set the context, providing a short overview of the key features of centre-local relations in England and how these have affected policy decisions during the pandemic. Secondly, it will assess local government's responses to the COVID-19 crisis against the approach of central government, focusing in particular on dynamics of resilience, innovation and leadership. This will allow for a critical reflection on the system of vertical relationships and allocation of power in the context of the pandemic. Finally, the conclusions will explore what could be done to improve centre-local relations going forward.

\section{Centre-local disconnect}

Like any large-scale crisis, the coronavirus outbreak has put government structures under considerable strain in most countries. The UK is no exception. However, as Dunleavy (1995: 52) reminds us, the UK is also 'unusually prone to policy mistakes' - and this tendency has become even starker during the pandemic. From the poor management of Personal Protective Equipment (PPE) provisions to the continued delays in providing a working track and trace system, COVID-19 has exposed in a drastic manner central government propensity to policy blunders. Yet, such missteps do not happen by default. Structural features of governance systems play a key role: they interact with and can amplify policy failure, making shortcomings 
more likely (Gaskell et al, 2020:523). Put simply, the depth and spread of power, decisionmaking points, collaboration, resources and capacity are crucial in determining the effectiveness of policy (as well as political) choices and responses, especially in a time of crisis.

From this angle, the centralised nature of subnational governance in the UK has been instrumental in generating 'glitches in the system' and, in turn, in producing flawed responses during the pandemic. This is particularly true in England, where local government lacks any constitutional protection and adequate power, central-local relations remain distinctively skewed towards the centre, and devolution is still a piecemeal project ${ }^{1}$ (Giovannini, 2020c; Giovannini, 2018; Leach et al, 2018). In the context of the COVID-19 crisis, this has allowed central government to enter in 'top-down command and control' mode: (re)centralising most decision-making in the face of the stark regional differences in the spread of COVID-19, without making any use of, and often ostracising, devolved and local government institutions (Giovannini, 2020c). As a result, 'one-size-fits-all' approaches were privileged, leading to nation-wide, place-blind policy decisions taken by the centre with very limited local consultation.

In a similar guise, during the crisis resource and capacity have also been increasingly pulled towards at the centre. This is epitomised by the lack of sufficient financial support for local authorities which, on top of the impact of a decade of austerity (Gray and Barford, 2018), has left the local level depleted - with many councils now on the brink of financial collapse (BBC, 2020). For example, in England, the government has so far provided $£ 5.2 \mathrm{bn}$ in extra funds but councils anticipate spending $f 4.4 \mathrm{bn}$ more than expected on the pandemic this year, as well as incurring $f 2.8 \mathrm{bn}$ in losses from fees and charges, leaving them with a $\mathrm{f} 2 \mathrm{bn}$ shortfall (Institute for Fiscal Studies, 2020). Moreover, this does not account for the issues that will unfold in the next years, when the collapse in council tax revenue and business rates collection since lockdown will start to feed into council budgets (Institute for Fiscal Studies, 2020). Meanwhile, in terms of capacity, from the start of the crisis the government has made virtually no use of the unique local knowledge held by local authorities - relying primarily on datadriven modelling to inform decision-making processes, while also centralising policy implementation (Gaskell et al, 2020).

Communication was also a point of contention. Central government held no direct line of contact with local councils and regularly imposed decisions that would affect directly their areas at the last minute, often through press releases, and without consultation - as in the case of the local lockdowns announced in the summer and autumn (Giovannini, 2020a). Similarly, paucity of information and intelligence left multi-agency partnerships aimed at supporting local communities during the COVID-19 emergency, such as Local Resilience Forums, feeling isolated from national decision-making and unable to effectively plan and strategize responses (Peters, 2020). In essence, throughout the crisis the government has mainly engaged in 'broadcasting', instructing localities formally with regulations and guidance at the last minute, rather than developing a constructive dialogue (Studdert, 2020).

This central-local disconnect is not new and councils in England have wrestled with it for a long time. However, in the context of the pandemic, it has intensified even further:

\footnotetext{
${ }^{1}$ Currently, the process of devolution in England is based on 'devolution deals' stipulated by central government with combined authorities (i.e. groups of councils that oversee these deals, under the lead of a directly elected 'metro-mayor' in most cases). So far, ten city-regions (Greater Manchester, Liverpool City Region, Tees Valley, the West of England, the West Midlands, Cambridgeshire \& Peterborough, London, Sheffield City Region, North of Tyne and West Yorkshire - all with mayors) and a rural area (Cornwall, without mayor) have a devolution deal. This gives them specific investment funds and power over some policy areas such as transport, housing and skills. These funding and policy competence vary from deal to deal (see Sandford, 2020a; Giovannini, 2018).
} 
considerably undermining the ability of the system to flex and respond to the crisis. The expertise and capacity of subnational levels of governance has been persistently overlooked by the centre. As a result, pandemic responses have been poorer and more prone to failure (Studdert, 2020). And yet, this has not deterred local authorities. The next section will focus on this, assessing the responses and resilience of local government throughout the evolution of the COVID-19 crisis in the face of central government's constraints.

\section{Local government resilience}

Despite often lacking power, direct control of essential resources and data, local government has shown considerable resilience during the pandemic. In the absence of adequate support from the centre, local authorities have made use of their leadership and horizontal collaborations, taking innovative and at times radical steps to provide effective and fast responses and continue to deliver essential services. This process, however, has been uneven and punctuated by obstacles - exposing the weaknesses of England's patchwork system of subnational governance. Analysing these dynamics while they are still in flux, as it is the case at the time of writing, is a complex task that requires a degree of systematization. To facilitate this, looking at the period since the start of the pandemic it is possible to identify, broadly, two phases characterised by specific approaches and responses to the crisis at the local level, and an incremental amplification of tensions between local and national government.

\section{Resilience and innovation.}

The first phase coincides roughly with the first COVID-19 wave (spring to early summer 2020), and is underpinned by resilience, innovation and experimentation, within broader compliance to national parameters, at the local level. During this period, local responses have varied in terms of range, scope and scale. In general, however, early indicators suggest that local knowledge, awareness of and sensitivity to place, existing and new horizontal partnerships, as well as a compassionate understanding of communities' needs on the part of local authorities were crucial in the development of effective practices (LGA, 2020). Drawing on research conducted by the New Local Government Network (NLGN, 2020) helps to assess some of the key factors that have shaped this type of responses.

Firstly, evidence shows that local authorities acted very fast to facilitate and support community-led responses to COVID-19 - and are now doing the same to aid recovery (NLGN, 2020). For instance, many councils created ad hoc grant schemes to help existing community and volunteer groups remain financially stable. Examples of these include Lambeth, where the local authority created a dedicated crowdfunding scheme to support projects tackling the impact of COVID-19 in their communities (NLGN, 2020). Kirklees and Staffordshire councils increased wards budgets for councillors to pass funding onto community groups; and Hounslow and St. Albans are among the councils that have funded community projects promoting mental well-being and tackling social isolation linked to lockdown (NLGN, 2020). The creation of these grants is an important indicator of local authorities' approach to the crisis. Unlike central government, they sought to coordinate and support grassroots responses, rather than controlling them from the top-down. Furthermore, drawing on existing relationships and mobilitating new ones, allowed local authorities to act much faster and effectively.

Secondly, and related to the previous point, horizontal collaborations and partnerships between councils and other local organisations were successfully activated to respond to COVID-19 (NLGN, 2020). These spanned a wide range of areas in terms of focus and remit, proving essential support to all key sectors of local society. For example, Birmingham Children's Partnership set up a new early help and grant programme to support children and 
families during the pandemic. Calderdale worked with West Yorkshire Fire and Rescue Service to deliver food parcels to residents in need; and Cambridgeshire launched a mental health campaign with several local partners to help residents cope with loneliness and access support (NLGN, 2020). Cross-council collaborations were also developed. For instance, 15 councils in the Yorkshire and Humber region set up 'Relationship Matters' to provide a support net for families experiencing relationship difficulties during lockdown (NLGN, 2020).

Thirdly, some councils were aided in their responses by action at the city-region level showing that, despite lacking substantial power and resources, these new institutions can make a difference (Sandford, 2020b). For example, combined authorities used their collaborative practices, spending power, assets and capacities to mitigate some of the immediate effects of the pandemic. In Greater Manchester for instance, constituent councils worked together to share data and create an 'early warning system' for the city-region's care homes.

Fourthly, directly elected metro mayors used their leadership and mobilised their public profile to bring local communities' concerns onto the national stage and lobby central government. Examples include the mayors of Greater Manchester, Sheffield City Region and West Midlands combined authorities who, during this first phase, repeatedly put central government under scrutiny on national media for the inadequateness of its responses emphasising the need for access to centralised data, calling for the extension of support for rough sleepers, and lobbing successfully for localised control of data and testing and tracing (Halliday, Mclntyre and Walker, 2020).

Finally, across these activities, councils showed both creativity and compassion - not only providing essential services, but also finding imaginative ways to raise spirits, especially for those members of local communities who struggled to cope with lockdown. For instance, Stockport council donated tablet devices to every care home in the borough to enable isolated elderly residents to keep in touch with their families; while Lancashire council set up a campaign encouraging members of the public to send cards to local care homes (NLGN, 2020).

Overall, this analysis suggests that, almost against all odds, during this first phase local government managed to foster resilience and innovation and provide critical support to their communities - showing what is possible when leadership is rooted locally. And yet, during and after the first COVID-19 wave, central government continued to stick to its top-down approach to crisis management, displaying very little willingness to learn from, and support, the local level $^{2}$. Besides rhetoric and grand slogans, additional funding for local government materialised late and in insufficient amounts - pushing many councils to the verge of bankruptcy. Nevertheless, local authorities continued to comply with government measures, mainly to preserve the local and national interest. However, the announcement of the softening of lockdown measures at the beginning of the summer, and the confusion that stemmed from it, signalled a change of direction (Shrimsley et al, 2020). This was the point when COVID-19 restriction rules started to diverge not only across the four nations of the UK, but also within England. However, the lack of a coherent system of subnational governance in the largest nation of the country meant that new territorial frictions started to emerge opening a new phase in centre-local relations during the pandemic.

\footnotetext{
2 The only notable exception was the recruitment of Leeds City Council's CEO from central government in May 2020 to help bridge the gap between national track and trace system and local councils, which are responsible for tackling large outbreaks.
} 


\section{Resistance and polarisation.}

This second phase (which started, roughly, in early summer 2020 and at the time of writing is still ongoing) is still characterised by local resilience in the face of central government topdown impositions. However, elements of resistance to central constraints also began to emerge incrementally. Locally rooted leadership was once again crucial, but this time it was used more overtly to challenge central government, rather than just balance out the effects of the latter's weak responses to the pandemic. In particular, further exacerbation of measures imposed by the centre onto the local level (epitomised by the imposition of local lockdowns without any consultation with local leaders), generated new disputes between these two tiers of government. Leicester is a case in point. In July, the mayor Peter Soulsby only found out about the immediate implementation of severe local restrictions in the city via a speech in Parliament by the Secretary of State for Health - without any prior knowledge and, crucially, without having access to infection rates data essential to manage the crisis on the ground (Calkin, 2020).

Since then, other areas in England were subject to local lockdowns, following similar top-down decisions from the government. Tensions started to mount at the local level, with leaders and mayors, from London to Newcastle, calling for clarity from the government, access to data and a seat at the table where decisions on lockdowns are made (Giovannini, 2020c). In particular, in areas with the highest levels of socio-economic deprivation (Raikes, Giovannini and Getzel, 2019) that were hit the hardest by COVID-19, central government's blunders were put once again under the spotlight by local representatives. They argued that new local lockdowns, with their vast socio-economic impact, were the price local areas had to pay because central government loosened national restrictions too early - pointing to a general failure of the national level to understand the importance of 'place' in the management of the crisis (Helm et al, 2020).

The government, however, persisted with its 'Whitehall knows best' approach. But this strategy proved again to be broadly ineffective - showing the limits of what some commentators have described as the "colonial mindset of the Cabinet" (Shrimsley et al, 2020). This, in turn, fed into the growing chasm between the local and the national level. On the one hand, local government continued to support their communities, as in the first phase, through horizontal collaborations, innovation in services, response delivery and local leadership. On the other, however, vertical relationships with the government deteriorated further. This was clearly reflected, for example, in central government's attempt to impose, in the autumn, the creation of unitary authorities ${ }^{3}$ as part of any new 'devolution deal' - which was read by many local leaders as a way to remove further powers from the local level. Besides, the postponement to an indefinite date of the long-awaited Devolution and Local Recovery White Paper, that was meant to provide clarity over the process of devolution in England, was also

\footnotetext{
${ }^{3}$ Local government structures in England vary from area to area. In most of England, local government operates on a 2-tiers structure (county and district), with responsibility for council services split between them. London, other metropolitan areas and parts of shire England operate under a single-tier structure with councils responsible for all services in their area. Overall, England's 343 local authorities are made up of 5 different types (county councils; district councils; unitary authorities; metropolitan districts; London boroughs). This complex system has been at the core of debates on local government reform for decades. In particular, there have been many attempts to create a homogeneous system made only of unitary authorities, so as to achieve, allegedly, more efficiency in service delivery and spending. The main criticism towards this approach is that there is no clear evidence that 'bigger is better' and that the creation of unitaries would make local government 'too big to be local' - especially considering that the average size of councils in England is already well above their European counterparts (Copus and Leach, 2020).
} 
interpreted by many in the local government sector as a withdrawal of support (in the form of autonomy, power and funding) to local authorities at a critical time (Giovannini, 2020b).

In addition, following a rise in infection rates in the North of England in the early autumn, central government introduced a new 3-tier lockdown system. This put large swathes of the region under tight restrictions (e.g. including hospitality closures), without providing any clarity over the financial support available to these areas to mitigate the impact of Tier-3 measures. This time around however, local leaders refused to comply, and the announcement of the new restrictions incited a tug-of-war between local and national leaders over support packages. In the face of the centre's perceived intransigence, mayors and council leaders sought to put 'place and communities' before politics, creating a cross-party alliance in the region. They stood up to central government and threatened to block the implementation of the new restrictions or to even take legal action, unless these measures were matched with a suitable financial package (Pidd, 2020). However, through the direct intervention of the Prime Minister (PM), the centre showed its determination to maintain a strong grip on local authorities, essentially challenging local leaders' claims and keeping them under its thumb. This can be partly explained by the fact that central government has very high political stakes in the North of England, especially in those former 'Red Wall' constituencies that switched their support from Labour to Conservatives for the first time in the 2019 general election and were crucial in delivering a victory for Johnson's party (Giovannini, 2020a; Mattinson, 2020). As a result, party politics got in the way of local and national pandemic policy. And while the North was the main battleground between the government and mayors, the struggles extended to other areas too - including London, where the PM threatened to take away mayoral control over the city's transport system (which needed significant extra funding due to reduced income during the pandemic).

The ramifications of these tensions are wide and complex - but for the purpose of this analysis, it is interesting to focus on how these events have exposed both the strengths and weaknesses of the piecemeal structures of subnational governance in England, and the power dynamics that stem from this. On the one hand, they highlight that despite its resilience, local government is still subject to a dominant centre - showing the persistence of the Westminster model and its power-hoarding nature. On the other, however, the resistance demonstrated by local actors over top-down government imposition is a reminder that 'devolution is a process, not an event' - and once set in motion, there are elements of it that cannot be controlled unilaterally from the centre (Giovannini, 2020a). This is particularly evident in the case of metro mayors. Since their creation in 2014, the government invested them with few formal powers and resources in an attempt to limit their leverage (Giovannini, 2018). However, metro mayors have quickly built a high local profile, which, in turn, is giving them growing informal powers and influence. This emerged very clearly during the second phase, as mayors stood up to the centre to protect their communities, gaining wide public attention. In this way, they successfully framed themselves as key political actors able to 'resist' against a distant and 'out of touch' government in London, while also putting the dysfunctional nature of centre-local relations in England squarely on the national stage.

Overall, during this second phase local government have again used innovative approaches in their responses to the pandemic. However, this time, agency and locally rooted leadership were effectively deployed to reveal the contradictions that underpin central government's approach to vertical power relations in the management of the crisis, and the policy (and perhaps also political) blunders that stem from it - with longer term consequences. 


\section{Conclusion: where do we go from here?}

The analysis developed in this chapter shed light on the dysfunctional nature of centre-local relations in England, assessing how the dynamics that underpinned them have deteriorated since the COVID-19 outbreak. In this way, it has illustrated the continued resilience of local government, the potential of its place-based responses and leadership, and its resistance towards an overcentralised system of multi-level governance. At the same time, the analysis has showed the extent to which local government is still held tight in central government's grip, as well as its persistence in disregarding local solutions and favouring, instead, centralised, top-down, one-size-fits-all policy responses. Crucially, this is becoming an issue not just for the local level, but for central government too - as its inability to understand, exploit and respond to local intelligence and leadership is leading to poorer decisions (Gaskell et al, 2020).

Thus, the pandemic has highlighted the presence of 'comorbidities' in England's body politics (Shrimsley et al, 2020), which affect its governance and policy outcomes. As a result, the COVID-19 crisis has thrown into sharp relief the urgent need to remedy these 'systemic weaknesses' developing healthier and more balanced multi-level governance dynamics going forward. This will be key to reduce the government's proneness to policy blunders and ensure all communities can bounce back and thrive.

International evidence supports this argument and clearly indicates that countries with a functioning system of multi-level governance have been more effective in their responses to the pandemic. For example, research from the OECD (2020:2) shows that introducing, activating and reorientating "existing multi-level coordination bodies that bring together national and subnational government representatives" is essential to "minimise the risk of a fragmented crisis response". They also emphasise that supporting cooperation across different levels of government is crucial, as it helps minimising "disjointed responses and competition for resources during a crisis" (OECD, 2020:2). Finally, the OECD suggests that adopting "a 'place based' or territorially sensitive approach to (...) recovery policies", while fostering "continuous dialogue between national and subnational governments" can lead to more efficient strategies for recovery (OECD, 2020:2). In essence, this work highlights that building strong relationships, based on collaboration between and across different levels of government, is vital to manage the crisis, produce better policy outcomes and built more resilient communities.

However, as the analysis in this chapter emphasises, so far in England there has been quite a stark deviation from these 'standards of good practice'. To address this, 'doing devolution properly', as the PM pledged in the run up to the 2019 general election, would be a first step in the right direction. This would require a change from the current system of ad hoc devolution deals (Giovannini, 2018) - embarking, instead, on a comprehensive programme of redistribution of power and funding to all areas across England.

But devolution alone is no panacea. 'Building back better' would also require a spirit of profound institutional as well as cultural reinvention, aimed at an overhaul of the very principles that underpin centre-local relations in England. Fixed hierarchies and competition should be replaced by vertical and horizontal cooperation, trust and fair share of power and resources. Sensitivity to place, diffused leadership and formal forums for dialogue between all government levels should supplant Whitehall dominance, 'top-down command and control' approaches and 'one-size-fits-all' measures. Crucially, any such programme of reform should involve not only local government, but the centre too. 


\section{REFERENCES:}

BBC (2020). Coronavirus: UK councils fear bankruptcy amid Covid-19 costs. BBC News website, 25 June 2020 https://www.bbc.co.uk/news/uk-53069772

Calkin, S. (2020). Leicester mayor hits back at government with new lockdown claims. Local Government Chronicle, 9 July 2020 https://www.lgcplus.com/politics/coronavirus/leicestermayor-hits-back-at-government-with-new-lockdown-claims-09-07-2020/

Copus, C. and Leach, S. (2020). Making the 'local' in local government count. Local Government Chronicle, 18 October 2020 https://www.lgcplus.com/politics/governance-andstructure/colin-copus-steve-leach-making-the-local-in-local-government-count-19-10-2020/

Dunleavy, P. (1995). Policy Disasters: Explaining the UK's Record. Public Policy and Administration, 10(2), 52-70.

Gaskell, J., Stoker, G., Jennings, W. and Devine, D. (2020). Covid-19 and the Blunders of our Governments: Long-run System Failings Aggravated by Political Choices. The Political Quarterly, 91, 523-533.

Giovannini, A. (2020a). The politics of the 'Red Wall' is coming home to roost. The Municipal Journal, 22 October 2020 https://www.themj.co.uk/The-politics-of-the-Red-Wall-is-cominghome-to-roost/218916

Giovannini, A. (2020b). Whatever Happened to Devolution? The Municipal Journal, 7 October 2020 https://www.themj.co.uk/Whatever-happened-to-devolution/218805

Giovannini, A. (2020c). COVID-19 and English Devolution. Political Insight, 11(3), p.40

Giovannini, A. (2018). "The uneven path of devolution deals in Yorkshire: opportunities, challenges and local (di)visions", in C. Berry and A. Giovannini (eds.) Developing England's North. The Political Economy of the Northern Powerhouse. Basingstoke: Palgrave.

Gray, M. and Barford, A. (2018). The depths of the cuts: the uneven geography of local government austerity, Cambridge Journal of Regions, Economy and Society, 11(3), p. 541563.

Halliday, J., Mclntyre, N. and Walker, P. (2020). Councils in England to be offered near realtime data on Covid cases. The Guardian, 7 August 2020

https://www.theguardian.com/society/2020/aug/06/councils-in-england-to-be-offerednear-real-time-data-on-covid-cases

Helm, T., Townsend, M., Coman, J. and McKie, R. (2020). Revolt over easing of coronavirus lockdown spreads as poll slump hits Boris Johnson. The Observer, 17 May 2020 https://www.theguardian.com/business/2020/mav/16/revolt-over-easing-lockdownspreads-as-poll-slump-hits-prime-minister

Institute for Fiscal Studies (2020), COVID-19 and English council funding: how are budgets being hit in 2020-21? 
Leach, S., Stewart, J. and Jones, G. (2018). Centralisation, Devolution and the Future of Local Government in England. London: Routledge.

Mattinson, D. (2020). Beyond the Red Wall. Why Labour Lost, How the Conservatives Won and What Will Happen Next? London: Biteback

NLGN (2020). Councils and COVID-19: their responses. NLGN report series, March-July 2020 http://www.nlgn.org.uk/public/2020/councils-and-covid-19-their-response-final-edition/

OECD (2020). The territorial impact of COVID-19: Managing the crisis across levels of government. OECD Report: Policy Responses to COVID-19 Series, 2 June 2020.

Peters, D. (2020). Local areas left in the dark by government. The Municipal Journal, 13 May 2020 https://www.themj.co.uk/EXCLUSIVE-Local-areas-left-in-the-dark-bygovernment/217568

Pidd, H. (2020). North of England leaders vow to oppose lockdown without financial support. The Guardian, 8 October 2020 https://www.theguardian.com/world/2020/oct/08/north-ofengland-leaders-vow-to-oppose-lockdown-without-financial-support

Sandford, M. (2020a). Devolution to local government in England. House of Commons Library Briefing Paper Number 07029, 26 March 2020

https://researchbriefings.files.parliament.uk/documents/SN07029/SN07029.pdf

Sandford, M. (2020b). How might English metro-mayors adapt to the post-coronavirus world? Bennet Institute Blog, June 2020 https://www.bennettinstitute.cam.ac.uk/blog/howmight-english-metro-mayors-adapt-post-coronavi/

Shrimsley, R., Foster, P., Pickard, J., Dickie, M., Bounds, A. and Tighe, C. (2020). Will coronavirus break the UK? The Financial Times, 21 October 2020 https://www.ft.com/content/05bcdeed-ce2d-4009-a3bc-cf9bb71c43d5 